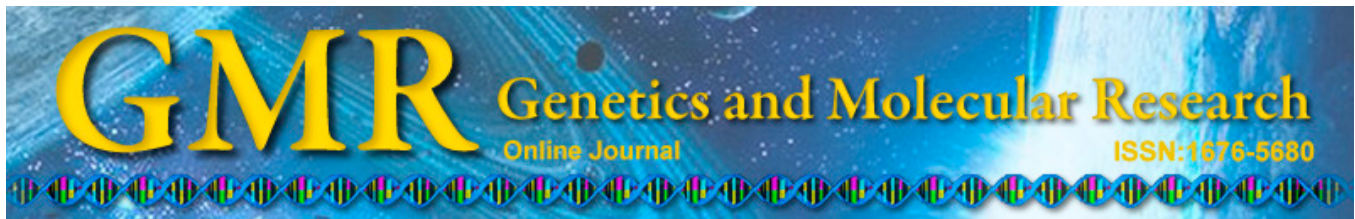

\title{
Expression and tyrosine phosphorylation of sp32 regulate the activation of the boar proacrosin/acrosin system
}

\author{
H.T. Dong, W.S. Shi, Y. Tian, L.P. Cao and Y. Jin \\ Agricultural College of Yanbian University, Yanji, China \\ Corresponding author: Y. Jin \\ E-mail: yijin@ybu.edu.cn
}

Genet. Mol. Res. 14 (1): 2374-2383 (2015)

Received June 6, 2014

Accepted October 17, 2014

Published March 27, 2015

DOI http://dx.doi.org/10.4238/2015.March.27.23

\begin{abstract}
The current study investigated the relationship between the level of expression and tyrosine phosphorylation of the sperm protein $32(\mathrm{sp} 32)$ and the activation of the boar proacrosin/acrosin system. The acrosomal membrane proteins of boar sperm for use in different treatment experiments (i.e., fresh sperm, freezing and thawing, capacitation, and acrosome reaction) were separated, stained by Coomassie brilliant blue, and analyzed using sodium dodecyl sulfate-polyacrylamide gel electrophoresis and western blot. The results showed that there were differences in the expression level of sp32 among capacitated, frozen-thawed, and post acrosomal reaction sperms. sp32 expression was higher and significantly higher in capacitated and post-acrosomal reaction sperms than in frozen-thawed sperms and fresh semen, respectively. The level of sp32 tyrosine phosphorylation was significantly different between the frozen-thawed sperms and sperms in the other experimental groups. However, bands with molecular masses of 38 to $170 \mathrm{ku}$ in the fresh semen group were more noticeable, indicating that large acrosomal membrane proteins underwent modification and degradation during capacitation and the acrosomal reaction. As a proacrosin binding protein, sp32 shows
\end{abstract}


upregulated expression and increase in tyrosine phosphorylation levels during the activation of the boar proacrosin/acrosin system.

Key words: sp32; Proacrosin; Acrosin; Tyrosine phosphorylation; Degradation

\section{INTRODUCTION}

Sperm protein 32 (sp32) is located in the acrosome of boar sperm. It specifically binds with proacrosin and acrosin intermediates, participating in capacitation and fertilization. Sp32 has 14 phosporylation sites, of which 3 are tyrosine residues (Tardif et al., 2001). In other words, sp32 is one of the sperm proteins that specifically binds with proacrosin and finely regulates sperm capacitation and fertilization (Arcelay et al., 2008).

Capacitation is a prerequisite for fertilization. Sperm proteins must go through a series of changes and modifications before fertilization. The changes and modifications include glycosylation of proacrosin, alterations in lipids, and increases in cAMP and surface negative charge (Ijiri et al., 2012). Despite the fact that the mechanism underlying capacitation is not entirely clear, there are numerous studies implicating the involvement of cAMP-dependent tyrosine phosphorylation in capacitation (Ficarro et al., 2003). Studies have shown that tyrosine phosphorylation may be regulated by cAMP and $\mathrm{Ca}^{2+}$ (Harayama et al., 2010). In the meantime, bicarbonate, reactive oxygen species, and protein kinase may also be key factors in capacitation (Harrison and Gadella, 2005; Arcelay et al., 2008; de Lamirande and O'Flaherty, 2008). Through in vitro experimentation, Tardif et al. (2001) cultured boar sperm in capacitation and non-capacitation media, or an ionophore-induced acrosome reaction, and isolated sperm proteins from each, which were then screened with anti-phosphotyrosine after separation with sodium dodecyl sulfate-polyacrylamide gel electrophoresis (SDS-PAGE). They found a protein band of $32 \mathrm{ku}$ in sperms that were cultured in capacitation medium or after induction of the acrosomal reaction, while this 32-ku band did not appear in sperms cultured in non-capacitation medium. They called this new 32-ku protein P32 and suggested that it may participate in capacitation. Recently, Bailey et al. (2005) studied P32 phosphorylation using proteomic approaches and showed that P32 is involved in capacitation. At the same time, Dubé et al. (2005) isolated proteins from capacitated and non-capacitated sperms, performed SDS-PAGE, and then examined the preparation with anti-sp32. They found that sp32 and P32 overlaps in western blot images. Through analysis of P32 with mass spectrometry, they showed that sp32 and P32 are identical with respect to their amino acid sequences (Dubé et al., 2005). This indicates that P32 is phosphorylated sp32, and the phosphorylation accompanies boar sperm capacitation. In addition, sp32 plays an important role in the maturation of acrosin (Tardif et al., 2003). Therefore, sp32 is involved in capacitation through tyrosine phosphorylation and binds with proacrosin. However, the mechanism of sp32 in proacrosin maturation is not clear.

In the current investigation, acrosomal proteins were analyzed via immunoblotting. The relationship between fertilization and sp32 level as well as its tyrosine phosphorylation level was determined. The purpose was to provide references for the long-term storage of boar semen. 


\section{MATERIAL AND METHODS}

\section{Animals}

Semen was collected from healthy adult large white boar from Yanji Animal Farm Ltd. After collection, semen samples were kept in insulated cups and transferred to the laboratory within $2 \mathrm{~h}$. During transportation, the semen samples were kept at $24^{\circ} \pm 2^{\circ} \mathrm{C}$. The semen samples met the following requirements: 1) white, 2) viability $>80 \%$, and 3) acrosome integrity $>75 \%$.

\section{Reagents and materials}

The following reagents were from Sigma: D-C6H12O6, $\mathrm{NaCl}, \mathrm{KCl}, \mathrm{NaHCO}_{3}$, ethylenediaminetetraacetic acid (EDTA), citrate disodium, $\mathrm{Na}_{2} \mathrm{HPO}_{4}$, bovine serum albumin (BSA), $\mathrm{MgCl}_{2}, \mathrm{KH}_{2} \mathrm{PO}_{4}, \mathrm{CaCl}_{2}$, Tris, and caffeine. The following reagents and materials were purchased from Beijing Huaxia Yuanyang Biotechnology Limited: Page Ruler Prestained Protein Ladder SM0671, polyvinylidene difluoride (PVDF) membrane, rabbit anti-porcine sp32 antibody, goat anti-rabbit $\operatorname{IgG}(\mathrm{H}+\mathrm{L}) \mathrm{HRP}$, mouse anti-phosphotyrosine, and goat anti-mouse $\operatorname{IgG}(\mathrm{H}+\mathrm{L}) \mathrm{HRP}$.

\section{Equipment}

The following equipment was used in the study: electronic scale, benchtop high-speed centrifuge, inverted microscope, laminar flow cabinet, vertical electrophoresis apparatus, electroblotter, UV spectrometer, and fluorescence microscope.

\section{Solution preparation}

\section{BTS}

The BTS was composed of $36.9 \mathrm{~g} \mathrm{D}-\mathrm{C}_{6} \mathrm{H}_{12} \mathrm{O}_{6}, 1.191 \mathrm{~g} \mathrm{NaCl}, 0.402 \mathrm{~g} \mathrm{KCl}, 1.260 \mathrm{~g}$ $\mathrm{NaHCO}_{3}, 1.247 \mathrm{~g}$ EDTA, and $50 \mathrm{mg}$ kanamycin sulfate. The solution was filtered through a $0.22-\mu \mathrm{m}$ Millipore filter and stored at $4{ }^{\circ} \mathrm{C}$ until use.

\section{PBS}

PBS was composed of $8.00 \mathrm{~g} \mathrm{NaCl}, 0.20 \mathrm{~g} \mathrm{KCl}, 1.56 \mathrm{~g} \mathrm{Na}_{2} \mathrm{HPO}_{4} \cdot 7 \mathrm{H}_{2} \mathrm{O}, 0.24 \mathrm{~g}$ $\mathrm{KH}_{2} \mathrm{PO}_{4}, 6.00 \mathrm{mg}$ penicillin, $5.00 \mathrm{mg}$ streptomycin, and $1000 \mathrm{~mL} \mathrm{H}_{2} \mathrm{O}$ q.s. The solution was filtered with $0.22-\mu \mathrm{m}$ Millipore filters and stored at $4^{\circ} \mathrm{C}$ until use.

\section{Basic dilution and freezing solution (BDFS)}

BDFS was composed of $3 \mathrm{~g} \mathrm{D}-\mathrm{C}_{6} \mathrm{H}_{12} \mathrm{O}_{6}, 4 \mathrm{~g}$ lactose, and $100 \mathrm{~mL} \mathrm{H} \mathrm{H}_{2} \mathrm{O}$ q.s.

\section{Dilution and freezing medium (DFM)}

For this, $22 \mathrm{~mL}$ fresh egg yolk was added to 78 boiled BDFS, supplemented with 10 IU penicillin, $10 \mathrm{IU}$ streptomycin, and $5 \mathrm{~mL}$ glycerol. DFM was freshly made. 


\section{Capacitation solution}

The capacitation solution was composed of $3.31 \mathrm{~g} \mathrm{NaCl}, 0.112 \mathrm{~g} \mathrm{KCl}, 0.4739 \mathrm{~g}$ $\mathrm{CaCl}_{2}, 1.212 \mathrm{~g}$ Tris, $0.991 \mathrm{~g} \mathrm{D}-\mathrm{C}_{6} \mathrm{H}_{12} \mathrm{O}_{6}, 0.275 \mathrm{~g}$ sodium pyruvate, $0.194 \mathrm{~g}$ caffeine, $0.5 \mathrm{~g}$ BSA, $1.0 \mathrm{mg}$ gentamycin, and $500 \mathrm{~mL}$ ultrapure $\mathrm{H}_{2} \mathrm{O}$ q. s., with $\mathrm{pH}$ ranging from 7.6 to 7.8. The solution was then filtered with a $0.22-\mu \mathrm{m}$ Millipore filter and stored at $4{ }^{\circ} \mathrm{C}$ until use.

\subsection{PBS}

The 0.01 M PBS was composed of $0.8 \mathrm{~g} \mathrm{NaCl}, 0.20 \mathrm{~g} \mathrm{KCl}, 0.144 \mathrm{~g} \mathrm{Na}_{2} \mathrm{HPO}_{4}, 0.02$ $\mathrm{g} \mathrm{KH}_{2} \mathrm{PO}_{4}$, and $100 \mathrm{~mL}$ deionized $\mathrm{H}_{2} \mathrm{O}$ q.s. The solution was adjusted to $\mathrm{pH} 7.4$ with 0.1 $\mathrm{M} \mathrm{HCl}$.

\section{Membrane protein extraction solution}

The membrane protein extraction solution was composed of $1.21 \mathrm{~g}$ Tris, $0.5 \mathrm{~mL}$ NP40, $0.7 \mathrm{~g} \mathrm{NaCl}, 0.087 \mathrm{~g} \mathrm{MgCl} \cdot 6 \mathrm{H}_{2} \mathrm{O}, 0.0288 \mathrm{~g}$ EDTA- $\mathrm{Na}_{2}, 0.5 \mathrm{~mL}$ pheylmethylsulfonyl fluoride, and $100 \mathrm{~mL}$ deionized $\mathrm{H} 2 \mathrm{O}$ q.s.

\section{Antibody dilution}

The primary antibody was diluted, with dilutions ranging from 1:2000 to 5000, and the secondary antibody was diluted, with dilutions ranging from 1:5000 to 100,000, by using PBS and stored at $4^{\circ} \mathrm{C}$ in the dark.

\section{Diaminobenzidine (DAB) coloration solution}

The DAB color solution was composed of $6.0 \mathrm{mg}$ DAB, $10.0 \mathrm{~mL}$ PBS, $0.1 \mathrm{~mL}$ ammonium nickel sulfate, and $1.0 \mu \mathrm{L} \mathrm{H}_{2} \mathrm{O}_{2}$.

\section{Methods}

\section{Conventional examination of semen}

Semen samples were set at room temperature $\left(20^{\circ}-23^{\circ} \mathrm{C}\right)$ for $2 \mathrm{~h}$ and then examined under a microscope at $37^{\circ} \mathrm{C}$. Semen samples that were milky white in color; had an ordinary smell; and exhibited normal sperm morphology, viability $>0.7$, and high density were used for further study. Each sample had a dense portion $(80-150 \mathrm{~mL})$.

\section{Viability test}

An aliquot of $100 \mu \mathrm{L}$ semen samples was placed on a blood cell counting chamber preheated to $37^{\circ} \mathrm{C}$ and counted under a $20 \mathrm{X}$ objective lens. For the 25 x 16 chamber:

$$
\text { Sperms } / \mathrm{mL}=(\text { sperms in } 80 \text { squares }) / 80 \times 400 \times 10000 \times \text { dilution factor } \quad \text { (Equation } 1)
$$


Viable sperms $/ \mathrm{mL}=($ viable sperms in 80 squares) $/ 80 \times 400 \times 10,000 \times$ x dilution factor (Equation 2)

$$
\text { Viable rate }=(\text { viable sperms/total sperms }) \times 100 \quad \text { (Equation } 3)
$$

\section{Wash}

Semen samples were diluted 1:5 with PBS and spun for 10 min at $1500 \mathrm{rpm}$; the wash was repeated 3 times. The cell pellet was saved for further use.

\section{Capacitation treatment}

Washed sperms were diluted 1:1 (v/v) with PBS adjusted to room temperature and spun at $500 \mathrm{rpm}$ for $5 \mathrm{~min}$. After removal of the supernatant, the sperm pellet was suspended with $2 \mathrm{~mL}$ capacitation solution and spun at $500 \mathrm{rpm}$ for $5 \mathrm{~min}$. The pellet was subsequently mixed with $2 \mathrm{~mL}$ capacitation solution containing $20 \mu \mathrm{g} / \mathrm{mL}$ sodium heparin and $50 \mu \mathrm{g} / \mathrm{mL}$ BSA. The sperms were then immediately incubated at $37.0^{\circ} \mathrm{C}$ in an incubator containing $5 \%$ $\mathrm{CO}_{2}$ for $4 \mathrm{~h}$. The swim-up method was used for capacitation (Esteves et al., 2000).

\section{Frozen treatment}

Washed sperms were diluted 1:2-5 with DFM, aliquoted into $0.25-\mathrm{mL}$ plastic tubes, which were then wrapped with 10 to 12 layers of gauze, and chilled in a refrigerator at $4{ }^{\circ} \mathrm{C}$ for 3 to $4 \mathrm{~h}$. The aliquots were then placed at 5 to $10 \mathrm{~cm}$ above liquid nitrogen for $10 \mathrm{~min}$ and finally dipped into liquid nitrogen for long-term storage.

\section{Thawing of frozen sperms}

Frozen sperms were taken out of the liquid nitrogen, placed into a prewarmed $\left(58^{\circ} \mathrm{C}\right)$ water bath for $8 \mathrm{~s}$, and then removed from the water bath.

\section{Acrosome reaction}

Sperms collected using the swim-up method were mixed with calcium ionophore A23187 ( $2 \mu \mathrm{M}$, dissolved in DMSO) and incubated for $30 \mathrm{~min}$.

\section{Semen quality examination}

An aliquot of $50 \mu \mathrm{L}$ semen sample was diluted in $1 \mathrm{~mL}$ PBS and incubated for 20 min at $37^{\circ} \mathrm{C}$. Then, an aliquot of $20 \mu \mathrm{L}$ diluted semen was loaded to a water bath $\left(37^{\circ} \mathrm{C}\right)$ and examined under a $40 \mathrm{X}$ objective lens.

\section{Coomassie brilliant blue staining}

An aliquot of $20 \mu \mathrm{L}$ PBS was smeared onto a glass slide, and dried and stained with 
Coomassie brilliant blue for $30 \mathrm{~min}$. The slides were washed three times with triple distilled water, dried, sealed with neutral resin, and examined under a light microscope (Moller et al., 1990).

\section{Acrosomal membrane protein isolation}

Fresh semen samples were washed with $0.01 \mathrm{M}$ PBS, centrifuged at $2500 \mathrm{rpm}$ for 10 $\min$. The procedure was repeated 3 times. The samples were washed again 3 times with 0.01 $\mathrm{M}$ Tris- $\mathrm{HCl}$ and centrifuged at $2500 \mathrm{rpm}$ for $10 \mathrm{~min}$. The pellet was finally suspended in 0.01 $\mathrm{M}$ Tris- $\mathrm{HCl}$, and mixed with a membrane protein extraction solution; $1.5 \mathrm{~h}$ later, the aliquot was centrifuged at $1500 \mathrm{~g}$ for $20 \mathrm{~min}$. The supernatant was transferred to a dialysis tube and dialyzed for $2 \mathrm{~h}$ in deionized water; it was then dialyzed in $0.01 \mathrm{M}$ Tris- $\mathrm{HCl}$ for $24 \mathrm{~h}$ with replacement of the solution several times. The membrane protein preparation was stored in aliquots at $-80^{\circ} \mathrm{C}$. The supernatant was washed with an extraction solution without NP-40 and then stored at $-20^{\circ} \mathrm{C}$.

\section{SDS-PAGE}

The sample concentration was measured using a UV spectrometer. Protein concentrations were adjusted to the same level. A $45-\mu \mathrm{L}$ volume was loaded for each protein sample. The electrophoresis condition was $40 \mathrm{~mA}$ for the condensation gel and $80 \mathrm{~mA}$ for the separation gel. The electrophoresis took about 3 to $4 \mathrm{~h}$. After electrophoresis, the gel was stained with Coomassie brilliant blue. A parallel gel was directly blotted.

\section{Western blotting}

Twenty layers of filter paper and PVDF membrane were cut into the same size as the gel and soaked in transferring buffer for 30 min until there was no air bubble between the sheets. Then, blotting was setup in the following order: positive electrode, 10 layers of filter, PVDF membrane, 10 layers of filter paper, and negative electrode. The filter, gel, and PVDF membrane were aligned, and no air bubble was present between the layers. Transfer was conducted with $1 \mathrm{~mA} / \mathrm{cm}$ for $1 \mathrm{~h}$. The membrane was washed with $0.01 \mathrm{M}$ PBS after blotting and then blocked in blocking buffer, with shaking at room temperature for $2 \mathrm{~h}$. The membrane was washed again with $0.01 \mathrm{M}$ PBS and incubated with the primary antibody at $4{ }^{\circ} \mathrm{C}$ for $12 \mathrm{~h}$. The negative control was incubated with $1 \%$ BSA in place of the primary antibody, and all other steps were conducted in a similar manner. The membrane was washed with $0.01 \mathrm{M}$ PBS again after primary antibody incubation and then incubated with the secondary antibody at room temperature for $2 \mathrm{~h}$, with shaking. The membrane was washed again and soaked in color development buffer; it was placed in the dark until bands were visible. Band development was halted with the addition of double distilled water. The membrane was then photographed.

\section{Statistical analysis of results}

The results of the experiment were analyzed using Excel 2007; we used linear equation methods for our analyses. 


\section{RESULTS}

\section{SDS-PAGE analysis of acrosomal membrane proteins}

Figure 1 shows that, after SDS-PAGE, the acrosomal membrane proteins were primarily seen above $25 \mathrm{ku}$; the bands between 25 to $38 \mathrm{ku}$ were weak, while protein bands between 38 and $170 \mathrm{ku}$ were clear. Acrosomal membrane proteins from the prophase of the acrosomal reaction were clearer and darker than those from the other treatments. Proteins from capacitated and frozen-thawed sperms were similar in intensity, but the 32-ku band was more distinct in frozen-thawed sperms than that in capacitated sperms. Protein bands between 38 and $170 \mathrm{ku}$ were obvious with fresh sperms.

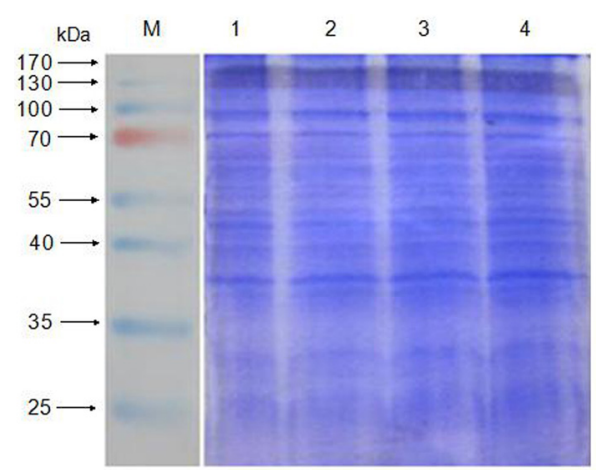

Figure 1. Acrosomal proteins from sperms treated with four different methods and separated with SDS-PAGE. Lane $M=$ marker; lane 1 = fresh sperm; lane 2 = capacitation sperm; lane 3 = frozen-thawed sperm; lane 4 = prophase of the acrosomal reaction sperm.

\section{sp32 in western blot of acrosomal membrane proteins}

Figure 2 shows an immunoblot for sp32. The membrane protein preparation from fresh boar sperms showed a faint band at $32 \mathrm{ku}$, while the preparation from frozen-thawed sperms showed a higher band density. Preparations from the acrosomal reaction and capacitated sperms in prophase showed the highest band density at $32 \mathrm{ku}$ (Table 1).

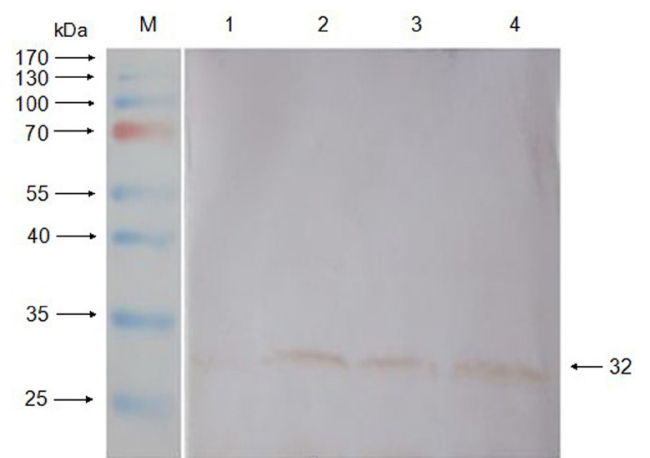

Figure 2. sp32 levels in acrosomal membrane protein preparations. Lane $M=$ marker; lane $1=$ fresh sperm; lane 2 = capacitated sperm; lane 3 = frozen-thawed sperm; lane 4 = prophase of the acrosomal reaction sperm. 
Table 1. Inverting total density of $\mathrm{sp} 32$.

\begin{tabular}{lc}
\hline Sperm treatments & Density \\
\hline Room temperature & $454,003.90$ \\
Capacitated & $673,085.90$ \\
Frozen-thawed & $469,221.12$ \\
Prophase of acrosomal reaction & $778,528.97$ \\
\hline
\end{tabular}

\section{Tyrosine phosphorylation in acrosomal membrane proteins}

Figure 3 shows an immunoblot of the acrosomal membrane proteins displayed with anti-phosphotyrosine. The results indicate that sp32 tyrosine phosphorylation in fresh and preacrosomal reaction sperms was lower than that in capacitated and frozen-thawed sperms. The tyrosine phosphorylation level was higher in sp32 of frozen-thawed sperms than that in sp32 of capacitated sperms. Other proteins in acrosomal-reaction sperms in prophase had almost no phosphorylation (Table 2).

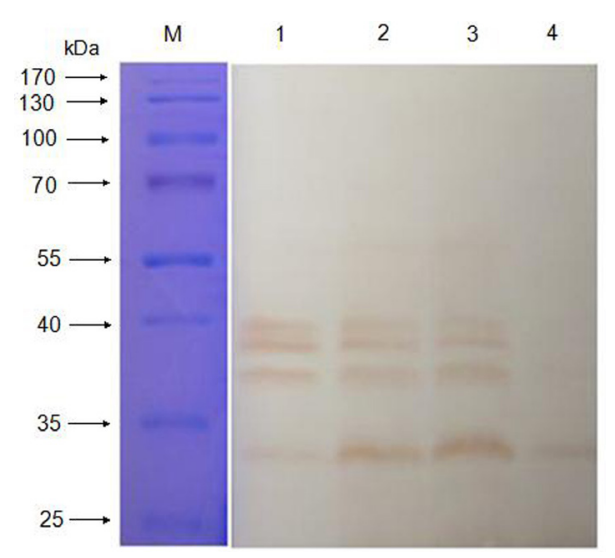

Figure 3. Acrosome membrane protein tyrosine phosphorylation in sperms after four treatments. Lane $M=$ marker; lane 1 = fresh sperm; lane 2 = capacitation sperm; lane $3=$ frozen-thawed sperm; lane 4 = prophase of the acrosome reaction sperm.

Table 2. Inverting total density of phosphorylated sp32.

\begin{tabular}{ll}
\hline Sperm treatments & Density \\
\hline Room temperature & $8,920.51$ \\
Capacitated & $19,871.88$ \\
Frozen-thawed & $21,415.21$ \\
Prophase of acrosomal reaction & $10,092.90$ \\
\hline
\end{tabular}

\section{DISCUSSION}

The results of SDS-PAGE showed that fresh sperms were clearly different from those of capacitated, frozen-thawed, and acrosomal reaction treatment sperms in acrosomal membrane proteins when the frozen-thawed sperms had $>30 \%$ viability. The differences were mainly seen in the region between 38 to $170 \mathrm{ku}$, where fresh sperms had denser bands; the other treatments had denser bands between 25 and $38 \mathrm{ku}$. These observations suggest that protein 
composition changes are closely related to capacitation during fertilization. sp32 was visible in capacitated and prophase acrosomal-reaction sperms but faint in fresh and frozen-thawed sperms. Capacitated and frozen-thawed sperms had similar levels of acrosomal membrane protein phosphorylation, but the frozen-thawed sperms had the highest level of sp32 tyrosine phosphorylation. These results indicate that frozen-thawed sperms may have a similar state and biochemical tag but that freezing damage obstructs fertilization (González-Fernández et al., 2009). The bands of tyrosine phosphorylation were faintly visible for sperms in the prophase of the acrosomal reaction, suggesting that related proteins were degraded or released during penetration of the zona pellucida (Sun et al., 2013). These observations suggest that the sp32 level and its tyrosine phosphorylation level regulate acrosomal protein activation, which, in turn, modulate the rate of fertilization. The results also showed that the phosphorylation of the 37- to 40-ku membrane proteins was especially stable in fresh, capacitated, and frozenthawed sperms. This observation is similar to that reported by Kalab et al. (1998) and Bravo et al. (2005); in these studies, 40- to 50- ku proteins were found to be stably phosphorylated before and after capacitation. Such unique stability may be another supplement for the innate tyrosine phosphorylation system in boar sperm.

sp32 is a highly conserved mammalian protein located in the head of sperm and has a 61-ku precursor. Baba et al. (1989) showed that sp32 conjugates and promotes proacrosin conversion into acrosin. Further analysis by this group showed that sp32 binding is specific; it binds with proacrosin of 55 and $53 \mathrm{ku}$, and the intermediate of $49 \mathrm{ku}$ but not the $43 \mathrm{ku}$ intermediate or the $35 \mathrm{ku}$ acrosin. Binding with the 55- and 53-ku proacrosin was stronger than binding with the 43-ku intermediate. Acrosin plays an important role in fertilization. The specific binding of sp32 with proacrosin illustrates the fine control of fertilization. It is believed that sp32 binds with proacrosin during the early stages of capacitation or the acrosomal reaction. Following the acrosome reaction in sperms, sp32 is not detectable, suggesting that sp32 may be degraded or released after the acrosomal reaction (Baba et al., 1994).

\section{CONCLUSIONS}

During the transition from capacitation to the acrosomal reaction, acrosomal membrane proteins are modified and degraded. In sperms incapable of fertilization, protein bands of 38 to $170 \mathrm{ku}$ appear more clearly, which is directly related to the fact that membrane proteins were not modified or activated. At the same time, the expression of the 32-ku protein was low. Sp32 was highly expressed in capacitated sperm or during prophase in the acrosomal reaction. This observation fits the expectation that sp32 is a special protein participating in sperm capacitation (Tardif et al., 2003), suggesting that the expression level of sp32 regulates acrosomal protein activation. Frozen-thawed sperms also displayed clear sp32 bands but had lower amounts of sp32 compared to those of capacitated sperms or during prophase of the acrosomal reaction. Although the sp32 tyrosine phosphorylation level is high, it is still different from that of capacitated normal sperms. The fact that sp32 tyrosine phosphorylation exceeded a "threshold" value indicates that boar sperms damaged by freezing will not undergo true capacitation or an acrosomal reaction.

\section{REFERENCES}

Arcelay E, Salicioni AM, Wertheimer E and Visconti PE (2008). Identification of proteins undergoing tyrosine 
phosphorylation during mouse sperm capacitation. Int. J. Dev. Biol. 52: 463-472.

Baba T, Michikawa Y, Kashiwabara S, Arai Y (1989). Proacrosin activation in the presence of a 32-kDa protein from boar spermatozoa. Biochem. Biophys. Res. Commun. 160: 1026-1032.

Baba T, Niida Y, Michikawa Y, Kashiwabara S, et al. (1994). An acrosomal protein, sp32, in mammalian sperm is a binding protein specific for two proacrosins and an acrosin intermediate. J. Biol. Chem. 269: 10133-10140.

Bailey JL, Tardif S, Dubé C, Beaulieu M, et al. (2005). Use of phosphoproteomics to study tyrosine kinase activity in capacitating boar sperm. Kinase activity and capacitation. Theriogenology 63: 599-614.

Bravo MM, Aparicio IM, Garcia-Herreros M, Gil MC, et al. (2005). Changes in tyrosine phosphorylation associated with true capacitation and capacitation-like state in boar spermatozoa. Mol. Reprod. Dev. 71: 88-96.

de Lamirande E and O'Flaherty C (2008). Sperm activation: role of reactive oxygen species and kinases. Biochim. Biophys. Acta 1784: 106-115.

Dubé C, Leclerc P, Baba T, Reyes-Moreno C, et al. (2005). The proacrosin binding protein, sp32, is tyrosine phosphorylated during capacitation of pig sperm. J. Androl. 26: 519-528.

Esteves SC, Sharma RK, Thomas AJ Jr and Agarwal A (2000). Effect of swim-up sperm washing and subsequent capacitation on acrosome status and functional membrane integrity of normal sperm. Int. J. Fertil. Womens Med. 45: 335-341.

Ficarro S, Chertihin O, Westbrook VA, White F, et al. (2003). Phosphoproteome analysis of capacitated human sperm. Evidence of tyrosine phosphorylation of a kinase-anchoring protein 3 and valosin-containing protein/p97 during capacitation. J. Biol. Chem. 278: 11579-11589.

González-Fernández L, Ortega-Ferrusola C, Macias-Garcia B, Salido GM, et al. (2009). Identification of protein tyrosine phosphatases and dual-specificity phosphatases in mammalian spermatozoa and their role in sperm motility and protein tyrosine phosphorylation. Biol. Reprod. 80: 1239-1252.

Harayama H, Nishijima K, Murase T, Sakase M, et al. (2010). Relationship of protein tyrosine phosphorylation state with tolerance to frozen storage and the potential to undergo cyclic AMP-dependent hyperactivation in the spermatozoa of Japanese Black bulls. Mol. Reprod. Dev. 77: 910-921.

Harrison RA and Gadella BM (2005). Bicarbonate-induced membrane processing in sperm capacitation. Theriogenology 63: 342-351.

Ijiri TW, Mahbub Hasan AK and Sato K (2012). Protein-tyrosine kinase signaling in the biological functions associated with sperm. J. Signal Transduct. 10: 1-18.

Kalab P, Peknicová J, Geussová G and Moos J (1998). Regulation of protein tyrosine phosphorylation in boar sperm through a cAMP-dependent pathway. Mol. Reprod. Dev. 51: 304-314.

Moller CC, Bleil JD, Kinloch RA and Wassarman PM (1990). Structural and functional relationships between mouse and hamster zona pellucida glycoproteins. Dev. Biol. 137: 276-286.

Sun PL, Yang LX, Cui JJ, Tian Y, et al. (2013). Activation of proacrosin accompanies upregulation of sp32 protein tyrosine phosphorylation in pig sperm. Genet. Mol. Res. 12: 6579-6587.

Tardif S, Dubé C, Chevalier S and Bailey JL (2001). Capacitation is associated with tyrosine phosphorylation and tyrosine kinase-like activity of pig sperm proteins. Biol. Reprod. 65: 784-792.

Tardif S, Dubé C and Bailey JL (2003). Porcine sperm capacitation and tyrosine kinase activity are dependent on bicarbonate and calcium but protein tyrosine phosphorylation is only associated with calcium. Biol. Reprod. 68: 207-213. 